\title{
CHROMOSOMAL LOCATION OF ZEIN GENES IN ZEA MAYS
}

\author{
G. VALENTINI,* C. SOAVE† and E. OTTAVIANO* \\ * Istituto di Genetica, Università, Via Celoria 10, Milano, Italy; † Laboratorio Biosintesi Vegetali \\ C.N.R., Via Celoria 2, Milano, Italy
}

Received 5.vi.78

\begin{abstract}
SUMMARY
Zein, the storage protein accumulated in maize endosperm, is composed of several polypeptides which can be separated by isoelectric-focusing (IEF) analysis. Much IEF zein variability is found when analysing different inbred lines-the number of bands varies from 8 to 15 and can occupy about 27 positions--and Fl endosperms show an additive parental pattern. Chromosomal location of factors controlling the phenotypic expression of eight IEF bands was studied by means of translocations between $\mathrm{A}$ and $\mathrm{B}$ chromosomes and trisomic stocks, which allowed a large part of the genome to be explored.

Three bands were shown to be controlled by factors localised on the analysed chromosome segments: one close to the $R$ locus on chromosome 10, one on the short arm of chromosome 4 and one on a segment composed of portions from the short arm of chromosome 9 and the long arm of chromosome 4.

The band controlled by the factor on chromosome 10 occupies the same IEF position as one which was found to be controlled by a factor on chromosome 7 near the opaque-2 locus. However, on the basis of SDS electrophoresis, these two polypeptides were found to have different molecular weights. The results obtained are discussed in relation to the molecular origin of zein heterogeneity.
\end{abstract}

\section{INTRODUCTION}

DURING seed formation maize endosperm accumulates large amounts of storage protein (zein). This group of proteins contains a number of polypeptides of similar molecular weight (23 and 21 kilodaltons) and amino acid composition but differing in their isoelectric point ( $\mathrm{pI}$ ) (Burr and Burr, 1976; Larkins et al., 1976; Giannazza et al., 1977). Isoelectric focusing (IEF) in polyacrylamide gels gives resolution of zein into 8 to 15 bands according to the genotype (Soave et al., 1976). This charge heterogeneity was found to be independent of the developmental stage of the endosperm or of environment interaction and to be due essentially to amino acid differences among the IEF zein components (Righetti and Gianazza, 1977). Furthermore, the in vitro translation products of polysomes engaged in zein synthesis show the same charge heterogeneity as native zein (Viotti et al., 1978). The study of several inbred lines of maize proved that the IEF pattern of zein was characteristic of the genotype and most of the strains gave different patterns (Gentinetta et al., 1975; Soave et al., 1976). The zein components of any individual inbred generally occupied 8 to 15 of about 28 discrete positions on the $p \mathrm{H}$ 6-9 gradient of the gel. The possible band positions were codified by progressive numbers from the more alkaline to the more acidic components (see fig. 1).

$$
42 / 1-\mathrm{c}
$$


In crosses between inbreds with different zein patterns, the two reciprocal Fl generations showed additive patterns and the amount of each component correlated with the gene dose present (Righetti et al., 1977). When seeds from the F2 generation were analysed, simple Mendelian segregation of IEF bands was observed. In a recent paper, Soave et al. (1978) showed that three zein bands (nos. 1, 2 and 3) appeared to be always associated together and with the zein regulatory gene opaque-2 (chr. 7 , pos. 16); two other bands (nos. 6 and 12) segregated independently of each other and of the three bands linked with the opaque-2 locus. These data indicated that factors responsible for the synthesis of some zein components were located in at least three different regions of the genome.

In order to obtain a better understanding of this complex system, which includes the regulatory genes floury-2 ( $f 12)$ and opaque-7 (o7) as well as opaque-2 (o2) more information is needed about structural genes, their localisation in the genome and relationships with regulatory genes. In this paper data concerning the chromosomal location of factors involved in zein synthesis are reported. The results obtained by isoelectric focusing and electrophoretic analysis are discussed in relation to the genetical origin of zein heterogeneity.

\section{Material AND Methods}

\section{(i) Maize stocks and genetic methodology}

Genetical analysis was based on the use of TB-A (translocations between $\mathrm{A}$ and $\mathrm{B}$ chromosomes) and trisomic lines. TB-A lines, first produced by Roman (1947), have a $18 \mathrm{~A}+2 \mathrm{~A}^{\mathrm{B}}+2 \mathrm{~B}^{\mathrm{A}}$ chromosomal constitution as a result of a translocation between $\mathrm{A}$ and $\mathrm{B}$ chromosomes. $\mathrm{A}^{\mathrm{B}}$ chromosomes are composed of the centric segment of an A chromosome and the acentric segment of a B chromosome, while the complementary rearrangement gives rise to $\mathrm{B}^{\mathrm{A}}$. More recently Raka and Robertson (1970) obtained TB-A lines in which the A segment joined to the centric portion of $B$ comes from translocations involving two $\mathrm{A}$ chromosomes, giving rise to $\mathrm{B}^{\mathrm{A} 1-\mathrm{A}^{2}}$ elements. Transmission of $\mathrm{B}^{\mathrm{A}}$ chromosomes was described by Roman (1947, 1948), Roman and Ullstrup (1951), Bianchi et al. (1961), Beckett (1975). TB-A lines have been used for gene chromosomal location by several authors (Bellini et al., 1961; Ottaviano, 1964; Peterson and Wernsman, 1964). The method relies on the high frequency of non-disjunction (70-90 per cent) of the $\mathrm{B}$ centromere at the second haploid mitosis of the male gametophyte, leading to two different spermatic nuclei in the same pollen grain: one with two $\mathrm{B}^{\mathrm{A}}$ chromosomes and the other lacking these elements. It follows that a cross between normal and TB-A male parents produces three types of progeny: (1) seeds having both endosperm and embryo with a balanced set of chromosomes, as a result of fertilisation by pollen with regular $\mathrm{B}$ centromere disjunction; (2) seeds with hypoploid embryo $\left(0 \mathrm{~B}^{\mathrm{A}}\right)$ and hyperploid endosperm $\left(2 \mathrm{~B}^{\mathrm{A}}\right)$; and (3) seeds with hyperploid embryo $\left(2 \mathrm{~B}^{\mathrm{A}}\right)$ and hypoploid endosperm $\left(0 \mathrm{~B}^{\mathrm{A}}\right)$ as results $(2$ and 3$)$, of the $\mathrm{B}^{\mathrm{A}}$ non-disjunction and of the two possible assortments of the $0 \mathrm{~B}^{\mathrm{A}}$ and $2 \mathrm{~B}^{\mathrm{A}}$ nuclei with the egg and the polar nuclei. Therefore recessive genes of the female parent located on the segment homologous to the one translocated to $\mathrm{B}^{\mathrm{A}}$, are phenotypically expressed in hypoploid Fl endosperms or embryos with a 
frequency related to the amount of non-disjunction and preferential fertilisation.

The use of this technique to localise genetic factors involved in the synthesis of IEF zein components requires that the female parental lines and TB-A lines be differentiated as regards the IEF pattern. For a given band, the female parent line must have the null allele and the TB-A line the plus allele, i.e. the former without and the latter with that band in their IEF pattern. If the allele controlling the synthesis of this zein component is located on the translocated segment, the F1 will show two IEF endosperm phenotypes: one without the band because of the hypoploid chromosomal set and the other with it as a result of normal hyperploid chromosomal complements. Normal and hyperploid genotypes could be distinguished only on the basis of a very clear dosage effect.

The material used and the crossing design are given in table 1. Each TB-A line (four to five plants) was used to pollinate plants of the tester lines, in order to check the translocation, and plants of two inbred lines (B73 and 38-11). These inbreds were selected because their IEF pattern did not reveal some bands typical of the TB-A genetical backgrounds (L289).

Two types of progeny were analysed by IEF on a single-kernel basis. One was derived from Tester/TB-A crosses. These progeny were taken into account only when the tester lines lacked bands typical of the TB-A strains. In such cases the absence of IEF bands due to the hypoploid state of the endosperm was confirmed by the phenotypic expression of the genetic marker.

A second group of progeny was obtained from B73/TB-A and 38-11/TBA crosses. For this material the IEF analysis was accompanied by cytological analysis of root tip mitosis. Only IEF bands not segregating in the parental lines were considered. Homozygosis was assessed by singlekernel IEF of 10-12 seeds per ear of each TB-A line.

Other progenies were obtained from lines trisomic for chromosomes 4, 6,7 and 10 respectively. The use of trisomic stocks in genetical analysis is described by Burnham (1962). An efficient chromosomal location of zein factors is to be expected if dosage effects can be clearly recognised. However, this was not the case in our study, mainly because of the variability of the genetic background of the material used. Only the progeny of trisomic 10, where different kernel types could be distinguished by means of genetic markers ( $R^{n j}$ and $R^{s t}$ : Navajo and stippled aleurone), yielded useful information. Single-kernel IEF analysis was made on seeds obtained by crossing $ᄋ R^{n j} R^{s t} r$ and $\hat{\sigma} r r$. The progeny was distinguished into: (1) trisomic with Navajo, stippled aleurone $\left(r R^{n j} R^{s t}\right)$; (2) disomic with colourless aleurone $(r r)$; (3) disomic and trisomic with Navajo aleurone $\left(R^{n j} r(r)\right)$; and (4) disomic and trisomic with stippled aleurone $\left(R^{s t} r(r)\right)$.

\section{(ii) Zein analysis}

Zein was extracted from individual endosperms essentially as described previously (Soave et al., 1977). About $150 \mu \mathrm{g}$ of zein was loaded on a gel slab containing 5 per cent acrylamide, 1 per cent ampholine $p H$ 6-8 range, 1 per cent ampholine $p H$ 7-9 range (LKB) and $6 \mathrm{M}$ urea.

The run lasted for 4 hours at $4^{\circ} \mathrm{C}$ and a constant $13 \mathrm{~W}$. Gels were stained with 0.05 per cent Coomassie Brilliant Blue R-250 in 20 per cent ethanol, 
10 per cent acetic acid. The molecular weight of the individual zein IEF bands was determined by cutting each band from an IEF gel and incubating the slices in $60 \mathrm{mM}$ Tris $p \mathrm{H} 6.8$ with $\mathrm{HCl}, 2$ per cent sodium dodecyl sulphate (SDS), 5 per cent 2-mercaptoethanol for 1 hour at $60^{\circ} \mathrm{C}$. The slices were then loaded on a 12 per cent SDS-acrylamide gel prepared as described by Laemmli (1970).

In some cases only half the kernel was used and the residual part containing the embryo was planted for cytological examination.

\section{Results}

Fig. 1 shows the IEF pattern of the inbreds L289, 38-1 1 and their F1 generation. Positions of the 27 possible zein IEF bands, traced by an extensive analysis of several inbred lines of maize, are also shown. Some differences (indicated by arrows) can be observed between the two parents, while the $\mathrm{Fl}$ is the combination of the patterns of the two parental genotypes.

Since most of the A-B translocations used in this work were in the L289 background, only those bands present in this parent and absent in the other (38-11 or B73) are useful for chromosomal location. These were bands nos. 12,16 and 20 in 38-11 and bands nos. 6, 8, 12 and 24 in B73 (table 1). In most of the cases, the seeds from the F1 generation did not segregate for the bands indicated above, pointing to the absence of factors responsible for the synthesis of these zein components in the chromosomal regions involved in each specific translocation. Only in the double translocation TB 4L-9S was a segregation observed, and then only for band 12; bands 16 and 20 (in 38-11) and 6, 8, 24 (in B73) appeared to be constant (fig. 2). Cytological examination indicated that all seeds carrying the zein component 12 had normal or hyperploid endosperm (normal or hypoploid embryos were observed at root tip mitosis) while all seeds lacking component 12 had hypoploid endosperm (hyperploid embryo).

Most of the F1 seeds from crosses between the L289 TB-A and the tester lines did not show segregation for any component of the zein IEF pattern. A positive result was obtained in the cross between the TB-4a (not included in L289 background) and the tester line su1/su1. In this case the hypoploid endosperms could be easily identified by the appearance of the sugary phenotype. Fig. 3 shows the zein IEF pattern of the line carrying the translocation, together with the pattern of the su1/su1 line and of some F1 seeds. The two parents differ in one zein band (no. 13) which is strong in TB-4a and weak in the su1/su1 line. In F1 seeds, band no. 13 segregated strong/weak and the weak phenotype was always associated with the sugary trait. A specific effect of sugary (su1) on band 13 can be ruled out; variation of this component is observed between normal lines (Soave et al., 1976) and comparison between normal and sugary endosperms did not show any effect on the proportion of zein IEF polypeptides (unpublished data).

Gene dosage effect on the zein IEF components was investigated by means of trisomics for chromosomes 4, 6, 7 and 10. As mentioned above, residual heterozygosity of the material, indicated by the segregation of many bands, precluded the finding of a very clear dosage effect related to chromosome number. In the case of chromosome 10, a strict association between a zein band (no. 2) and the trisomy was observed. Since the trisomy was identifiable by the effect of three alleles $r, R^{n j}$ and $R^{s t}$, we investigated the 


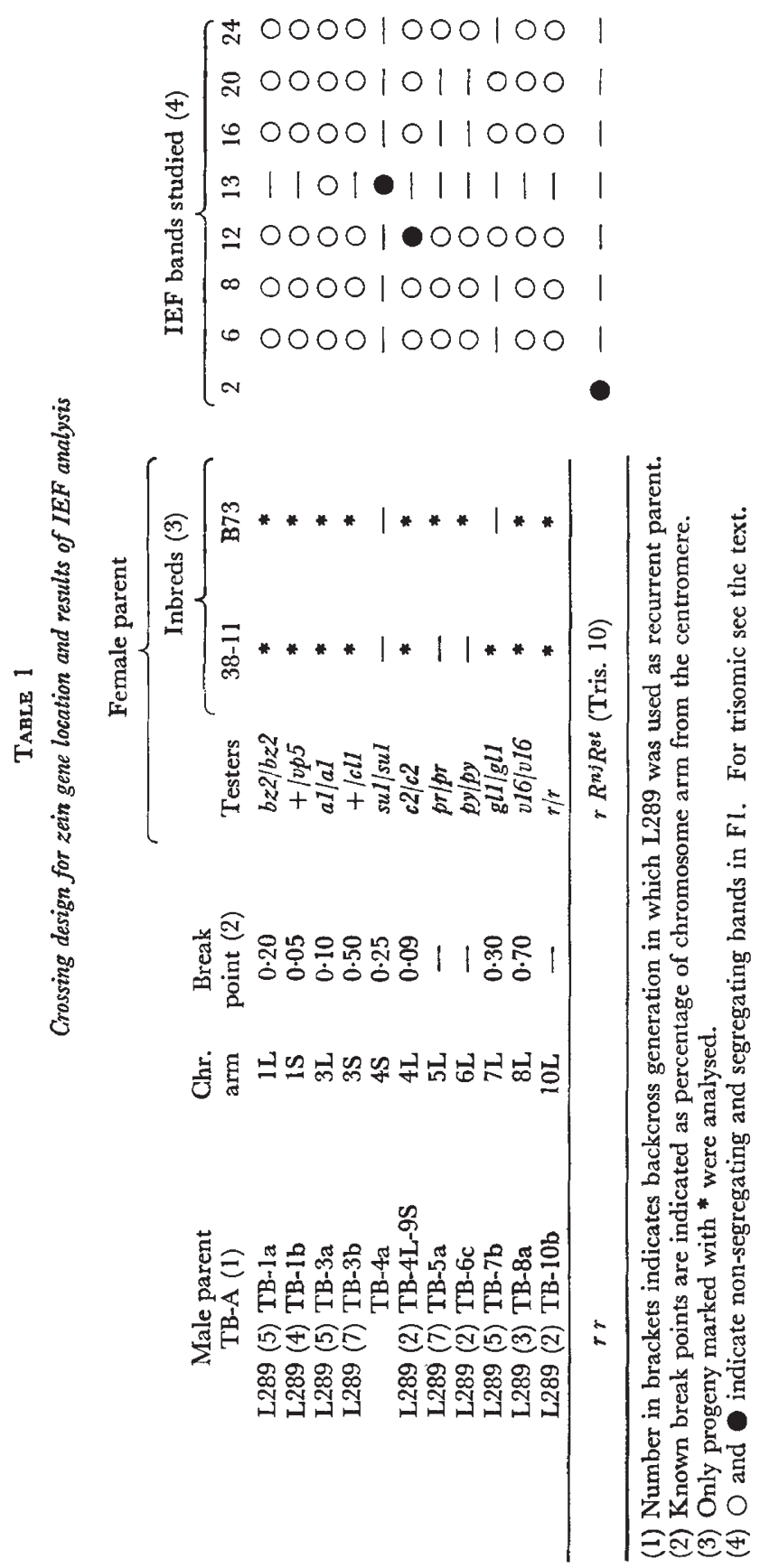


possible association of the band no. 2 with the $R$ locus. Fig. 4 shows the IEF pattern of zein extracted from endosperms with the following genotypes: $r R^{n j} R^{s t}, r r, r R^{n \jmath}(r), r R^{s t}(r)$.

It is clear that band no. 2 is present only in seeds containing $R^{s t}$ and absent in the others (table 2). Furthermore, in the pentasomic endosperms, band no. 2 shows higher intensity. This result indicates an association between a factor responsible for the synthesis of the zein component no. 2 and the $R$ locus on chromosome 10 (pos. 57).

The results obtained from genetical analysis are summarised in table 1 . Localisation was accomplished for factors controlling the bands nos. 2, 12 and 13, while those affecting all the others indicated in the table are not localised on chromosome segments involved in TB-A translocations.

TABLE 2

Analysis of IEF band no. 2 in progeny from trisomic-10 seed parent

$\begin{array}{llcc}\text { Phenotype } & \text { Genotype } & \begin{array}{c}\text { No. seeds } \\ \text { analysed }\end{array} & \begin{array}{c}\text { Band } \\ \text { no. } 2\end{array} \\ \text { (1) } r & r r r & 10 & - \\ \text { (2) } R^{n j} & r R^{n j} R^{n j}(r r) & 35 & - \\ \text { (3) } R^{s t} & r R^{s t} R^{s t}(r r) & 20 & + \\ \text { (4) } R^{n j} R^{s t} & r R^{n j} R^{n j} R^{s t} R^{s t} & 10 & ++\end{array}$

(2) and (3) include normal (triploid $r R^{n j} R^{n j}$ or $r R^{s t} R^{s t}$ ) and pentasomic $\left(r r r R^{n j} R^{n j}\right.$ or $r r r R^{s t} R^{s t}$ ) endosperms. - and + indicate absence and presence respectively; + + stands for higher intensity.

In order to see if these zein components were constituted of polypeptides exhibiting the same molecular weight (total zein is a mixture of chains of 23 and 21 kilodaltons), we analysed bands 2, 12 and 13 by SDS-polyacrylamide gel electrophoresis. Fig. 5 shows that bands 2 and 12 are of M.W. 23,000 and band 13 of 21,000 daltons. Furthermore, Soave et al. (1978) have found that one band, exhibiting the same IEF position as component no. 2 associated with the $R^{s t}$ allele, was linked with the opaque-2 locus in the inbreds $\mathrm{OH} 45$ and $\mathrm{OH} 43$. However, SDS-electrophoresis showed that this band is composed of polypeptides with a different M.W. (21,000 daltons) (fig. 5).

\section{Discussion}

Using TB-A and trisomic stocks, factors involved in the synthesis of zein IEF components were located in three different chromosomal regions: one very close to the $R$ locus (chromosome 10), one in the short arm of chromosome 4 and one in a segment composed of portions of two chromosomes (9 and 4). Our data do not show which of the two portions of the compound segment carries the factor controlling polypeptide 12 synthesis. However, it should be noted that TB-4L-9S translocation includes most of the long arm of chromosome 4, which is much larger than the portion of chromosome 9. Break-point distances from the centromere and genetical data provided by Raka and Robertson (1970) show that these portions include 98 and 17 physical units respectively. The scale is that reported by Neuffer et al. (1968).

The band located in chromosome 10 occupies the same IEF position as 
that found by Soave et al. (1978) which is regulated by a factor linked with .2 on chromosome 7 of $\mathrm{OH} 43$ and $\mathrm{OH} 45$ backgrounds. However, differences in molecular weight were revealed by SDS analysis: 23 kilodaltons for the polypeptide from trisomic stock and 21 kilodaltons for that from $\mathrm{OH} 43$ and OH45. In the two cases two different polypeptides exhibiting the same electrical charge were involved, indicating that similarity of positions of bands in IEF analysis does not necessarily mean that the bands represent the same gene product. The amount of zein polymorphism detected by IEF analysis, as evaluated taking into account many inbred lines (Gentinetta et al., 1975; Soave et al., 1976), is an underestimate of the polymorphism really existing in this material: similar phenotypes may frequently derive from different genotypes. Second, the number of genes controlling zein heterogeneity may be large. It can hardly be estimated on the basis of IEF analysis. The number of IEF positions observed in the line showing the highest resolution can be taken only as a minimum estimate of the number of genes.

Protein with similar isoionic points may be coded for by different genes, just as different alleles of the same gene may determine proteins at different IEF positions. Both IEF analysis and SDS electrophoresis are needed to resolve the system.

We may reject the hypothesis that the zein variability is due to posttranscriptional modifications on the following grounds: (i) the hybrid IEF pattern and the gene dosage effect observed in endosperm from reciprocal crosses (Soave et al., 1976; Righetti et al., 1977) and (ii) the correspondence of heterogeneity in native and in vitro synthesised zein (Viotti et al., 1978). Thus it seems plausible to assume that a number of structural genes are involved in the synthesis of zein. However, the presence or absence of one of the many polypeptides might be the result of the action of either a structural or a regulatory gene.

Structural gene mutation leading to changes of polypeptide amino acid composition might result in a variation of the band position in the IEF map. In this case the replacement of one band by another is to be expected. However, the new band may escape observation through coinciding with an IEF position with a different gene product.

Deletion and nonsense mutations may result in the absence of IEF bands but again their effects may be masked by the presence of different gene products in the same positions. Another possible explanation for the presence or absence of a band is variation with respect to a regulatory gene, specifically controlling the expression of the structural gene coding for the polypeptide concerned.

A specific regulatory gene may exist for each structural element, in addition to such genes as $02, f 12, o 7$ which control the expression of all zein proteins (Gianazza et al., 1976; Soave et al., 1976; Di Fonzo et al., 1977) and which are not involved in the variability studied in this work.

The data presented in this paper show that genes controlling different zein components are scattered in different parts of the maize genome. It may be more than a coincidence that three of these genes are each in the same region as a general regulatory gene. One of these was found on the short arm of chromosome 4 which also includes $f 12$, another is on the long arm of chromosome 10 along with 07 , while a third one has been located by Soave et al. (1978) close to 02 . 
Acknowledgments.--We are very grateful to Dr N. Pogna for his co-operation in the cytological analysis and to Dr J. B. Beckett for supplying seed stocks of most TB-A strains used in this study. This work was supported in part by grant No. 75.01590.06 from Consiglio Nazionale delle Ricerche (G.N.R.).

\section{References}

Becketт, J. B. 1975. Genetic breakpoints of the A-B translocations of maize. Maize Genet. Coop. News Letter, 49, 130-134.

Bellini, G., BIANCHI, A., AND otTAviano, e. 1961. The use of interchanges involving Btype chromosomes in studying artificial mutagenesis in maize. Z. Vererbl., 92, 85-99.

BIANCHI, A., Bellini, G., Contin, M., AND ottaviano, E. 1961. Nondisjunction in presence of interchanges involving B-type chromosomes in maize, and some phenotypical consequences of meaning in maize breeding. Z. Vererbl., 92, 213-232.

burnham, c. R. 1962. Discussion in Cytogenetics, pp. 375. Burgess Publishing Co., Minneapolis.

BURR, B., AND BURR, F. A. 1976. Zein synthesis in maize endosperm by polyribosomes attached to protein bodies. Proc. Nat. Acad. Sci. USA, 73, 515-519.

DI FONZO, N., FORNASARI, E., SALAMINI, F., AND SOAVE, C. 1977. SDS-protein subunits in normal, opaque-2 and floury-2 maize endosperms. Maydica, 22, 77-88.

gentinetta, E., Maggiore, T., SAlamini, F., lorenzoni, G., Pioli, F., AND soave, c. 1975. Protein studies in 46 opaque-2 strains with modified endosperm texture. Maydica, 20, 145-164.

Gianazza, E., Righetti, P. G., PIOli, F., Galante, E., AND soave, C. 1976. Size and charge heterogeneity of zein in normal and opaque-2 maize endosperms. Maydica, 21, 1-17.

gianazza, E., Viglienghi, V., Righetti, P. G., SAlamini, F., AND soAve, G. 1977. Amino acid composition of zein molecular components. Phytochemistry, 16, 315-317.

LAEMMLI, U. K. 1970. Cleavage of structural proteins during assembly of the head of bacteriophage T4. Nature, 227, 680-685.

LARKINS, B. A., JONES, R. A., AND TSAI, C. Y. 1976. Isolation and in vitro translation of zein messenger ribonucleic acid. Biochemistry, 15, 5506-5511.

NEUfFer, M. G., JONES, L., AND zUBER, M. s. 1968. The mutants of maize. Crop Science Society of America, pp. 74.

ottavıano, E. 1964. Influenza di duplicazioni cromosomiche sulla grandezza delle cariossidi di mais. Maydica, 7, 99-114.

PETERSON, P. A., AND WERnSMAN, E. A. 1964. A monosomic type approach in maize breeding. Crop Science, 4, 533-535.

RAKHA, F. A., AND ROBERTSON, D. s. 1970. A new technique for the production of A-B translocations and their use in genetic analysis. Genetics, 65, 223-240.

RighetTI, P. G., GianAzZA, E., VIotTI, A., AND soAve, c. 1977. Heterogeneity of storage proteins in maize. Planta, 136, 115-123.

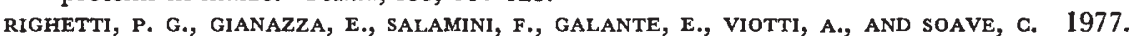
Zein: macromolecular properties, biosynthesis and genetic regulation. In Electrofocusing and Isotachophoresis, pp. 199-211. Walter de Gruyter \& Co., Berlin, 1977.

ROMAN, H. 1947. Mitotic non disjunction in the case of interchanges involving the B-type chromosome in maize. Genetics, 23, 391-409.

Roman, H. 1948. Selective fertilization in maize. Genetics, 33, 122.

Roman, H., AND Ullstrup, A. J. 1951. The use of A-B translocation to locate genes in maize. Agron. $\mathcal{J}_{\text {., }}$ 43, 450-454.

SOAVE, C., RighetTI, P. G., LoRENZONI, C., GENTINETTA, E., AND SAlAMini, F. 1976. Expressivity of the opaque-2 gene at the level of zein molecular components. Maydica, 21, 61-75.

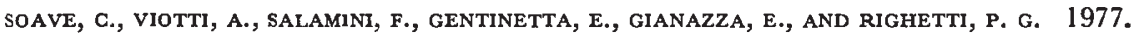
Techniques for the separation of seed proteins of maize. In Techniques for the Separation of Barley and Maize Proteins, pp. 61-68. Publ. by the Commission of the European Communities, Luxemburg.

SOAVE, C., SUMAN, N., AND SALAMINI, F. 1978. Linkage relationships between regulatory and structural gene loci involved in zein synthesis in maize. Theoret. Appl. Genetics, 52, 263-267.

Viotti, A., SALA, E., AlBeri, P., AND SOAVE, c. 1978. Heterogeneity of zein synthesized in vitro. Plant Sci. Letters, 13, 365-375). 

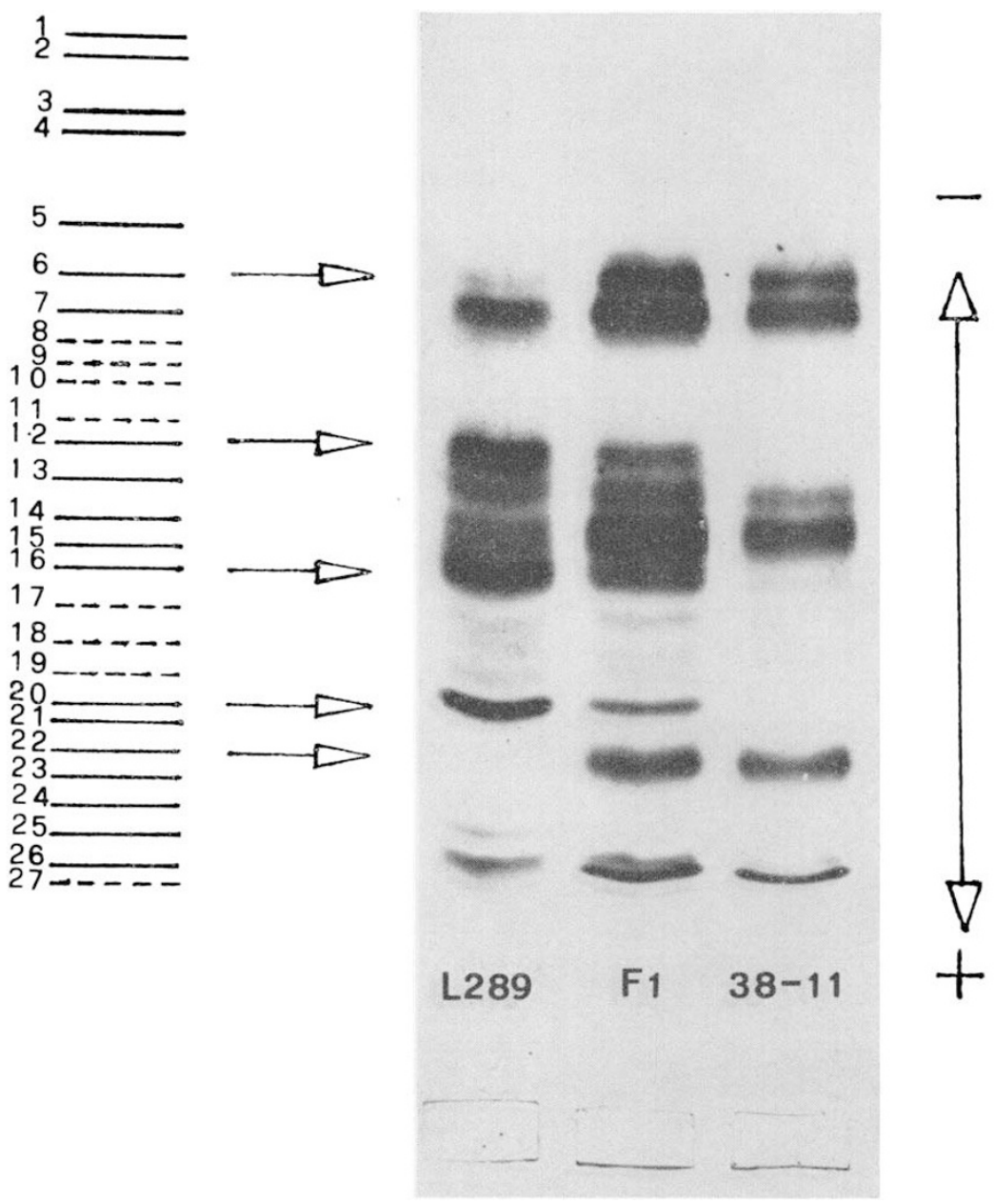

Plate I

FIG. 1.-Zein IEF phenotypes of L289, F1 and 38-11. On the left the IEF position of the all major (continuous line) and minor (dotted line) zein bands is reported. The arrows indicate the bands which differ between the two parents. 


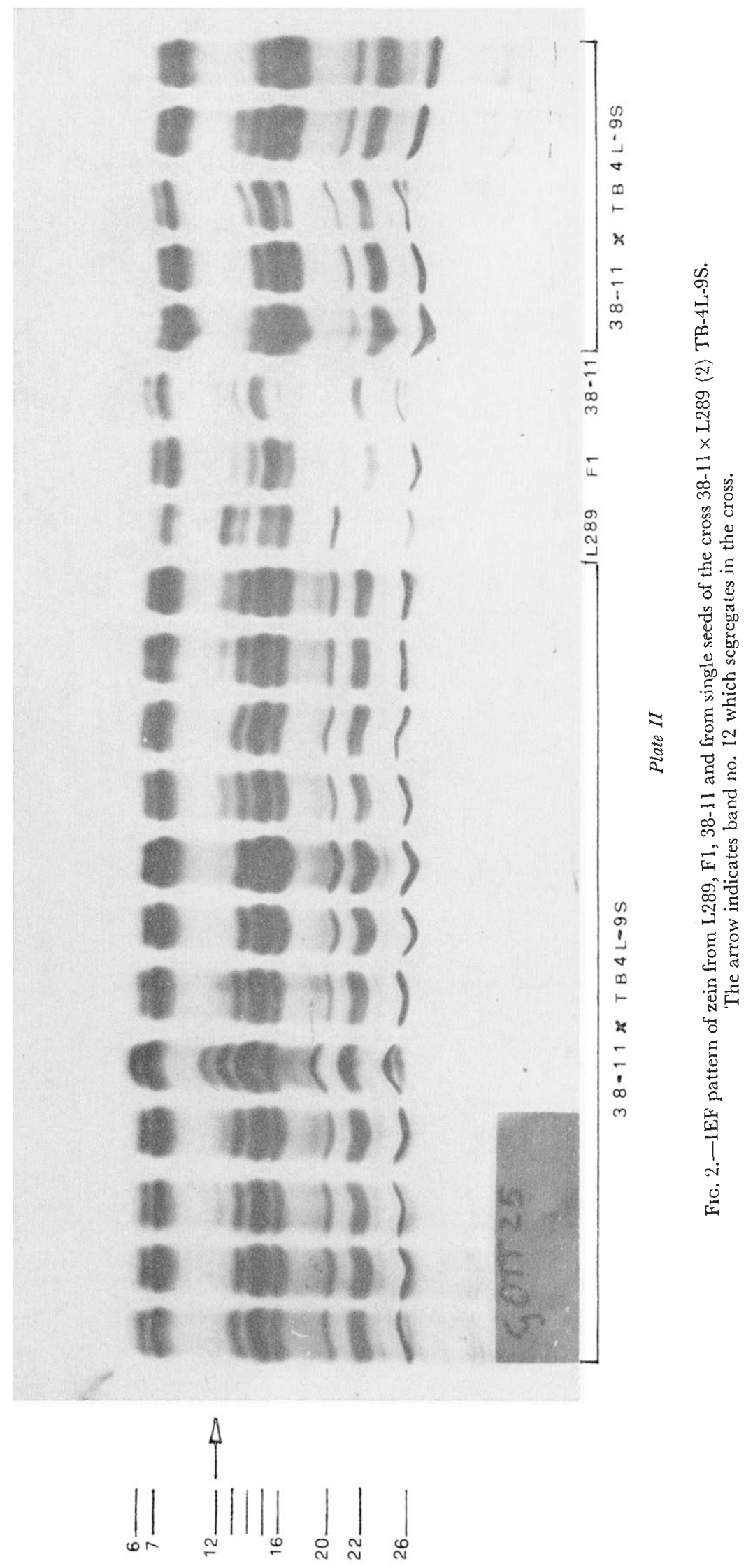



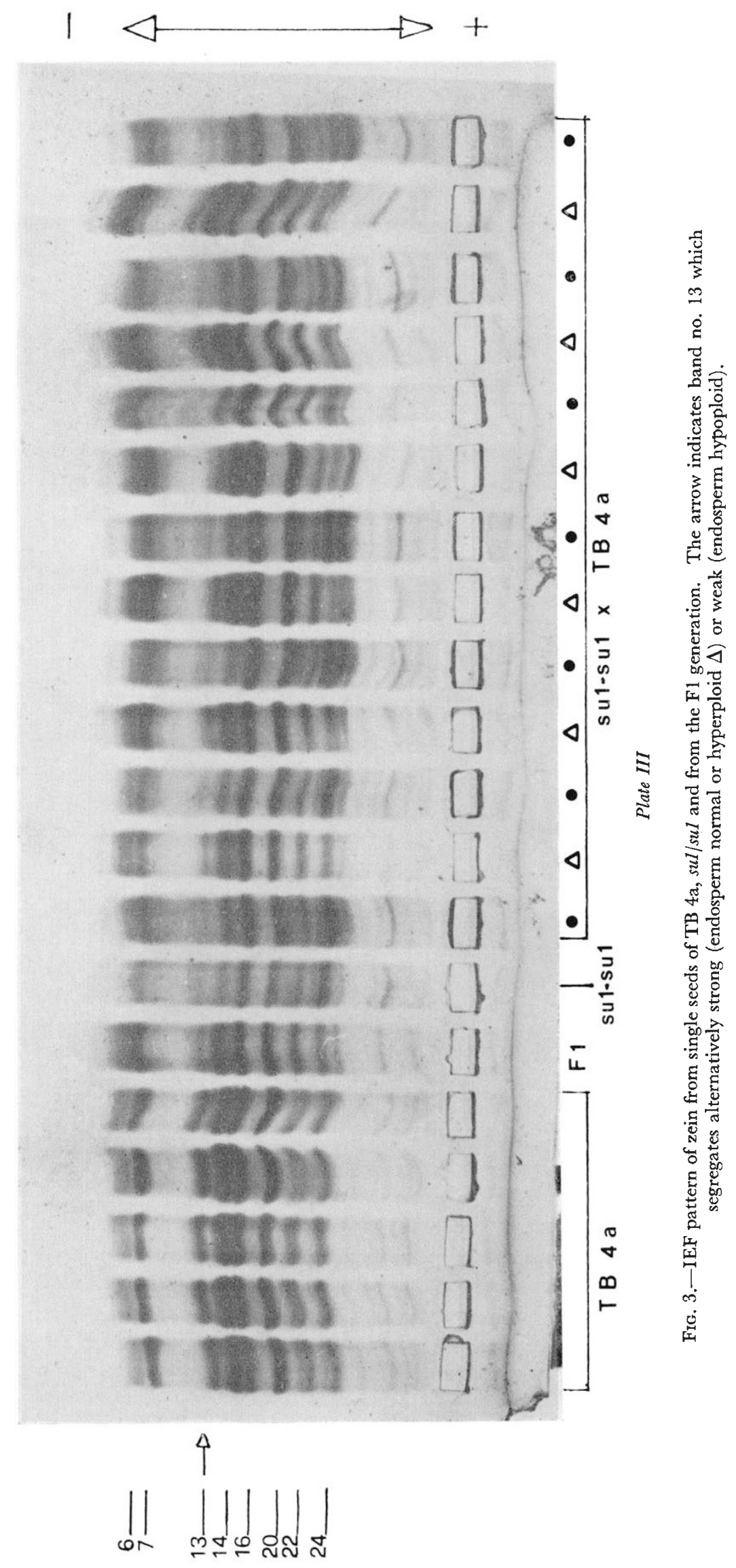


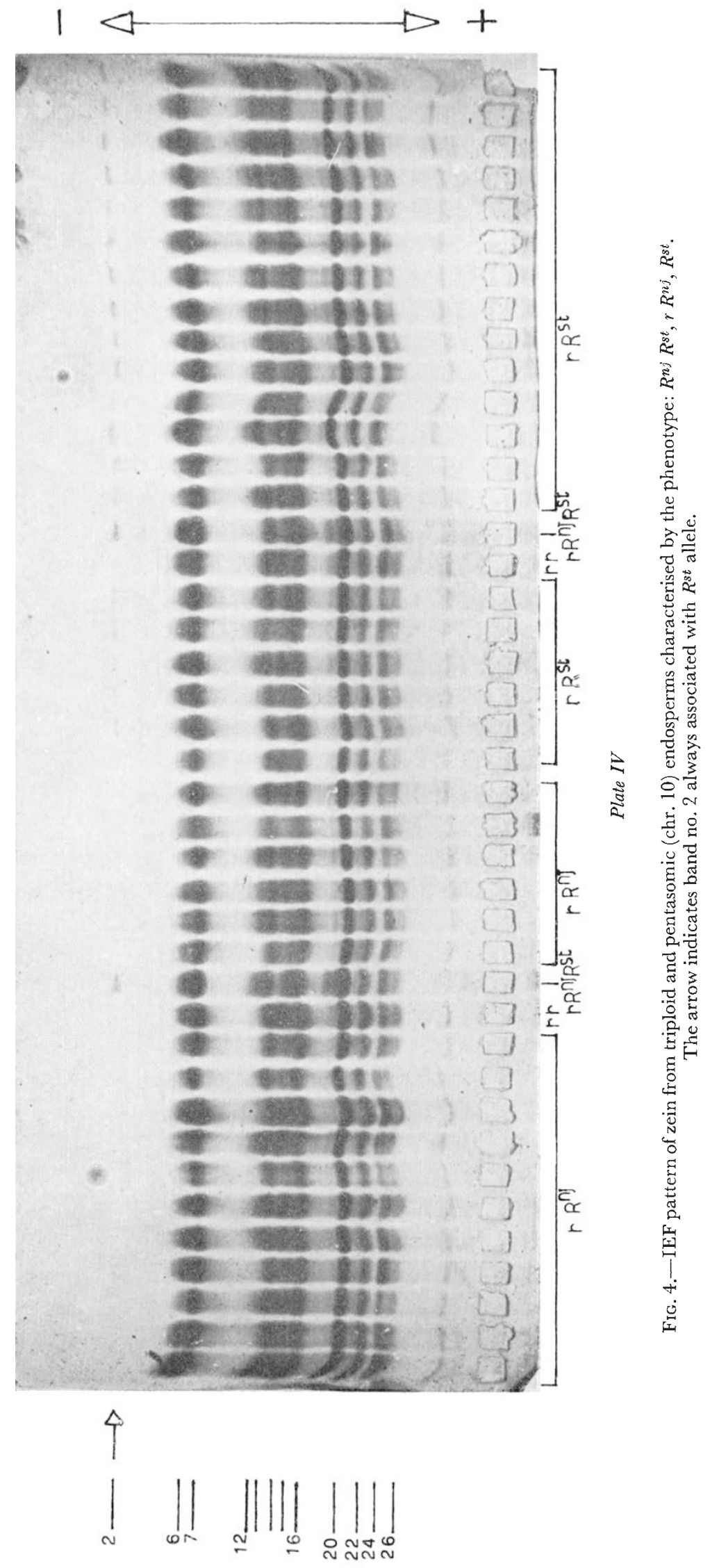




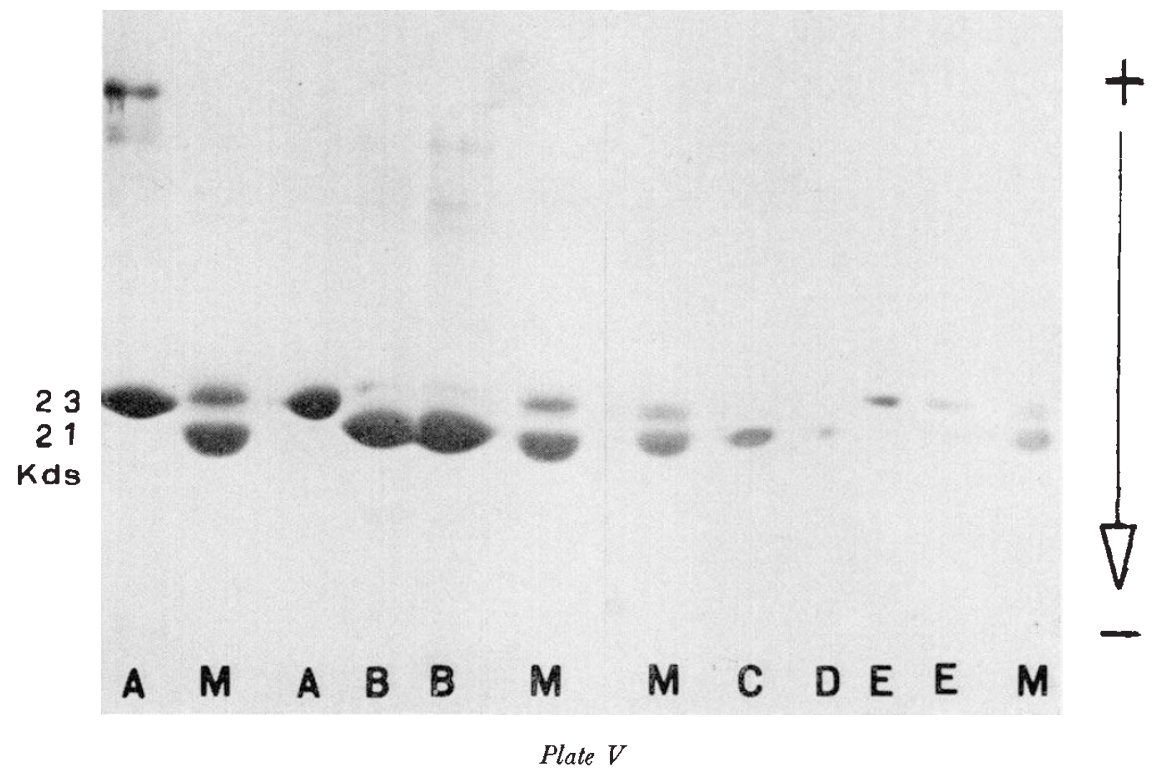

FIg. 5.-SDS analysis of IEF bands. A indicates band no. 12 from TB-4L9S and B band no. 13 from TB-4a. C, D and $\mathrm{E}$ are bands no. 2 from $\mathrm{OH} 45, \mathrm{OH} 43$ and $R^{s t}$ trisomic 10 respectively. $M$ refers to total zein proteins used as marker of molecular weight. 